\title{
Conformational Analysis and Near-Infrared-Induced Rotamerization of Malonic Acid in an Argon Matrix
}

\author{
Ermelinda M. S. Maçôas and Rui Fausto* \\ Department of Chemistry-CQC, Centro de Química de Coimbra, University of Coimbra, \\ P-3049 Coimbra, Portugal
}

\author{
Jan Lundell, Mika Pettersson, Leonid Khriachtchev, and Markku Räsänen \\ Laboratory of Physical Chemistry, University of Helsinki, P.O. Box 55 (A.I. Virtasen Aukio 1), \\ FIN-00014 Helsinki, Finland
}

Received: August 7, 2000; In Final Form: September 29, 2000

\begin{abstract}
Relative energies and vibrational spectra of the conformational states of a malonic acid monomer $\left(\mathrm{HOOCCH}_{2}-\right.$ $\mathrm{COOH}$ ) were calculated using various levels of approximation [Hartree-Fock (HF), Møller-Plesset to second order (MP2), and B3LYP density functional theory (DFT)]. The calculations predict the existence of six different conformers according to skeletal $\mathrm{C}-\mathrm{C}$ bond and $\mathrm{O}-\mathrm{H}$ bond rotation. Three conformers are found with energies close enough to enable their spectroscopic observation. The lowest-energy conformer (I) shows a nearly planar structure with an $\mathrm{OH} \cdots \mathrm{O}=\mathrm{C}$ intramolecular hydrogen bond closing a six-member $\mathrm{O}=\mathrm{C}-$ $\mathrm{CH}_{2}-\mathrm{C}-\mathrm{O}-\mathrm{H}$ ring. The second- and third-lower energy conformers (II and III) differ from the conformational ground state by less than $5 \mathrm{~kJ} \mathrm{~mol}^{-1}$. Conformers II and III adopt a cis arrangement around the $\mathrm{C}-\mathrm{O}$ bonds: conformer II exhibits the two carbonyl bonds in a nearly orthogonal arrangement, with one carboxylic group in the plane containing the carbon atoms, whereas in conformer III ( $C_{2}$ symmetry), the carbonyl bonds make a dihedral angle of ca. $120^{\circ}$, and both carboxylic groups are placed out of the plane containing the skeletal carbons. Their relative energy is predicted by the highest-level calculations to be ca. $1 \mathrm{~kJ} \mathrm{~mol}^{-1}$. The theoretical predictions agree with the analysis of the infrared spectra of monomeric malonic acid isolated in a solid argon matrix, where the presence of the three above-mentioned conformers was unequivocally identified. Narrowband tunable irradiation in the near-infrared region was found to promote efficiently the interconversion between the experimentally observed conformers.
\end{abstract}

\section{Introduction}

Malonic acid based compounds have been studied as inhibitors of matrix metalloproteinases involved in tissue remodeling and thus in various disease processes, including tumor invasion and joint destruction. ${ }^{1}$ Malonic acid based inhibitors were found to bind in a unique way to the enzymes, leading to a 5001000 -fold improvement in inhibitory potency when compared with more conventional inhibitors. ${ }^{1}$ The discovery of the specific binding of this new class of inhibitors was tentatively correlated with the molecular conformation of the malonic acid fragment at the inhibitor interaction sites. The selective conformer activity opens new perspectives in the design of more efficient drugs. However, the information available on the conformational properties of malonic acid is relatively scarce and concerns mainly the structure of its crystalline phases. ${ }^{2-9}$

Malonic acid was found to exist in three distinct crystalline varieties, depending on the temperature: phase $\gamma$ is stable below $48 \mathrm{~K} ;{ }^{2}$ phase $\beta$ is stable between 48 and $360 \mathrm{~K} ; 3,5$ and phase $\alpha$, which is the high-temperature phase, is stable above $360 \mathrm{~K} .{ }^{3,6}$ The room-temperature phase is a centrosymmetric triclinic crystal with two molecules per unit cell. Molecules are arranged in zigzag chains, with the hydrogen-bonded carboxyl groups forming two crystallographically and spectroscopically different rings, which are nearly orthogonal. ${ }^{5}$ The conformation of the

* To whom all correspondence should be addressed. individual molecules in this crystal is characterized by a nearly orthogonal arrangement of the two carboxylic groups (both in a cis configuration around the $\mathrm{C}-\mathrm{O}$ bond), with one carboxyl group being coplanar with the carbon skeleton (see Figure 1). ${ }^{7}$ Phase $\alpha$ is orthorhombic, with four molecules in the unit cell, and is characterized by hydrogen-bonded dimeric units linked through symmetry-equivalent carboxyl groups. As in phase $\beta$, the molecules form zigzag chains, but the carboxylic groups are related by a 2-fold symmetry axis., ${ }^{3,6}$ The individual molecules belong to the $C_{2}$ symmetry point group, with both carboxylic groups out of the plane of the carbon atoms adopting the cis arrangement around the $\mathrm{C}-\mathrm{O}$ bond (Figure 1). ${ }^{7}$

Monomeric malonic acid and its monoanion have been studied previously by Hartree-Fock ab initio self-consistent field (SCF)-molecular orbital (MO) calculations using smallsize basis sets (STO-3G and 4-21G) in order to explain the large dissociation constant ratio $k_{1} / k_{2}$. This ratio is usually exhibited by dicarboxylic acids where the monoanion can be stabilized by intramolecular hydrogen bonding. ${ }^{8}$ In this earlier study, it was suggested that nonplanar conformations of malonic acid are generally favored over the planar forms, stressing the importance of the steric repulsion between the two carboxylic groups. Nevertheless, the intramolecularly hydrogen-bonded planar structure was found to be the most stable conformer in the case of the monoanion. ${ }^{8}$ In a more recent paper, the HF/6$31 \mathrm{G}(\mathrm{d}, \mathrm{p})$ calculated vibrational frequencies of monomeric 


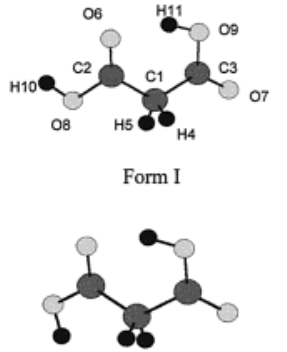

Form VI

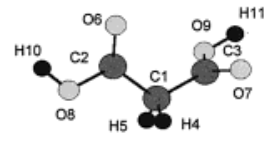

Form II

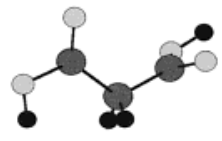

Form V

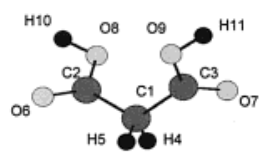

Form III

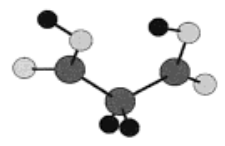

Form IV
Figure 1. Malonic acid predicted conformers according to HF/6-31G(d) calculations. In crystalline phases $\alpha$ and $\beta$, individual molecules assume conformations similar to forms II and III, respectively. Relative energies $\left(\mathrm{kJ} \mathrm{mol}^{-1}\right)$ and populations (\%) are as follows: (I, 9.05, 1.1); (II, 0.00, 65.9); (III, 1.65, 33.0); (IV, 24.21, $6.0 \times 10^{-3}$ ); (V, 31.14, $<1.0 \times 10^{-3}$ ); and (VI, 37.67, <1.0 × $10^{-3}$ ). The total energy of conformer II, accounting for the zero-point vibrational energy correction, is $-1090466.35 \mathrm{~kJ} \mathrm{~mol}^{-1}$.

malonic acid and larger dicarboxylic acids were used to test the possibility of developing a unified force field with a reasonable set of force constants for predicting solid-state spectra of these compounds. ${ }^{9}$ To the best of our knowledge, no further systematic structural or vibrational studies have been reported on malonic acid.

In this article, we present a detailed study of the conformational space of monomeric malonic acid. This study was undertaken with the use of high-level ab initio and density functional theory (DFT) calculations and matrix-isolation vibrational spectroscopy connected with selective near-infraredinduced rotamerization. In particular, the main factors that determine the stability of the different conformations and the photochemically induced interconversion processes between the lowest-energy species are analyzed.

\section{Experimental and Computational Details}

The matrix samples were prepared by continuously flushing a copper tube containing malonic acid (Aldrich, 99+\%), heated to $323 \mathrm{~K}$, with high-purity argon $(99.9999 \%)$. The gaseous mixture was deposited onto a cooled CsI window in a closecycle helium cryostat (APD, DE202A) at 7.5 K. The IR spectra (4000-450 $\mathrm{cm}^{-1}$ ) were measured using a Nicolet SX-60 FTIR spectrometer equipped with a liquid nitrogen cooled MCT detector and a $\mathrm{KBr}$ beam splitter, with spectral resolutions of 0.25 or $1.0 \mathrm{~cm}^{-1}$. Typically 200 interferograms were coadded. In our samples, monomeric species were formed almost exclusively, this was achieved by choosing an appropriate temperature for the substance container and optimizing the matrix-gas flow rate.

To promote conformational interconversions, tunable pulsed near-infrared (NIR) irradiation was used, as provided by the idler beam of an optical parametric oscillator (OPO Sunlite, Continuum). The pulse duration of the NIR irradiation was ca. $5 \mathrm{~ns}$, with a line width of $\sim 0.1 \mathrm{~cm}^{-1}$. The frequency of the NIR radiation was established with an accuracy better than 1 $\mathrm{cm}^{-1}$ by a Burleigh WA-4500 wavemeter used to control the OPO signal radiation wavelength.

$\mathrm{Ab}$ initio and DFT calculations ${ }^{10-12}$ were performed with GAUSSIAN 92/DFT or 94, ${ }^{13}$ on a DEC ALPHA 7000 computer at the Center of Informatics of the University of Coimbra (CIUC) and on an SGI Origin 2000 at the Center for Scientific Computing Ltd. (CSC, Espoo, Finland).

Optimized geometries and vibrational frequencies were calculated at three different levels of theory [Hartree-Fock
(HF), Møller-Plesset to second order (MP2), and density functional theory (DFT/B3LYP)]. Several basis sets with increasing degrees of flexibility were used, ranging from the moderate size $6-31 \mathrm{G}(\mathrm{d})$ to the extended $6-311++\mathrm{G}(3 \mathrm{dp}, 3 \mathrm{df})$ basis set. ${ }^{14,15}$

The force constants (symmetry internal coordinates) to be used in the normal coordinate analysis were obtained from the DFT Cartesian harmonic force constants [B3LYP/6-31G(d,p)] using the program TRANSFORMER. ${ }^{16}$ This program was also used to prepare the input data for the normal coordinate-analysis programs used in this study (BUILD-G and VIBRAT). ${ }^{17}$ The calculated frequencies (B3LYP) were then scaled with the use of a single scale factor $(0.9614){ }^{18}$

\section{Results and Discussion}

Molecular Geometries and Energetics. To find the stable conformations of malonic acid, we performed a systematic search on the HF/6-31G(d) potential energy surface (PES). These calculations are relatively inexpensive in computational terms and have been proven to yield reasonable structural data for similar compounds. ${ }^{8,18}$ We then used the HF/6-31G(d) calculations as a first estimate to the higher-level MP2 and DFT calculations.

In these preliminary calculations, the $\mathrm{O}=\mathrm{C}-\mathrm{C}-\mathrm{C}$ dihedrals of the initial structures submitted to geometry optimization were varied by $60^{\circ}$ within the range $0-360^{\circ}$, and the initial $\mathrm{O}=\mathrm{C}-$ $\mathrm{O}-\mathrm{H}$ dihedrals were made equal to $0^{\circ}$ or $180^{\circ}$ (all nonequivalent-by-symmetry combinations of the dihedrals were considered). The HF/6-31G(d) calculations predict the existence of six distinct conformers with nonplanar skeletons (see Figure 1). The three lowest-energy conformers (I, II, and III in Figure 1) are predicted to have relative energies differing by less than $10 \mathrm{~kJ} \mathrm{~mol}^{-1}$, whereas the remaining conformers correspond to high-energy forms.

Conformer II is predicted by the HF/6-31G(d) calculations to be the lowest-energy form. It has two carboxylic groups in a nearly orthogonal arrangement; one of these groups is coplanar with the carbon atom backbone. In conformer III (belonging to the $C_{2}$ symmetry point group), the carbonyl bonds make a dihedral angle of ca. $120^{\circ}$, and both carboxylic groups are placed out of the plane containing the carbons. Conformers II and III adopt a cis arrangement around the $\mathrm{C}-\mathrm{O}$ bonds. Both of these structures have been described previously by low-level HF calculations. ${ }^{8}$ Conformer I is predicted to have an energy higher than that of conformer II or III, and it shows a nearly planar structure, with an $\mathrm{OH} \cdots \mathrm{O}=\mathrm{C}$ intramolecular hydrogen bond closing a six-member $\mathrm{O}=\mathrm{C}-\mathrm{CH}_{2}-\mathrm{C}-\mathrm{O}-\mathrm{H}$ ring.

Figure 1 also gives the calculated relative populations of the various conformers at $323 \mathrm{~K}$, which is the temperature used to prepare the gas-phase samples deposited onto the matrix window for IR data collection. The HF/6-31G(d) calculated relative energies were taken into account and a Boltzmann distribution was assumed. Because the relative populations of the three lessstable conformers of malonic acid are too low to enable their spectroscopic observation under the experimental conditions used in this study, the highest-level calculations (MP2 and DFT/ B3LYP) were undertaken only for the three most stable conformers.

The MP2 and B3LYP relative energies, calculated using different basis sets, are presented in Table 1. Table 2 shows the optimized MP2 geometries for conformers I, II, and III, calculated using the largest $6-311++\mathrm{G}(3 \mathrm{df}, 3 \mathrm{pd})$ basis set considered in this study.

The B3LYP results are not significantly affected by changing the basis set. Conformer $\mathbf{I}$ is always predicted to be the most 
TABLE 1: B3LYP and MP2 Relative Energies $\left(\mathrm{kJ} \mathrm{mol}^{-1}\right)$ of the Three Most Stable Conformers of Malonic Acid

\begin{tabular}{cccc}
\hline conformer & $6-31 \mathrm{G}(\mathrm{d}, \mathrm{p})$ & $6-311++\mathrm{G}(2 \mathrm{~d}, 2 \mathrm{p})$ & $6-311++\mathrm{G}(3 \mathrm{df}, 3 \mathrm{pd})$ \\
\hline \multirow{3}{*}{ I } & 0.00 & DFT/B3LYP \\
I & 5.29 & 0.00 & 0.00 \\
II $^{a}$ & 5.35 & 3.40 & 3.83 \\
III & & 4.35 & 4.81 \\
& 3.58 & MP2 & \\
I & 0.00 & 0.33 & 0.00 \\
II $^{a}$ & 0.31 & 0.00 & 0.28 \\
III & & 0.65 & 1.09
\end{tabular}

${ }^{a}$ Doubly degenerated conformer.

TABLE 2: Geometric Parameters of Malonic Acid Conformers Obtained at the MP2/6-311++G(3df,3pd) Level of Theory

\begin{tabular}{|c|c|c|c|}
\hline \multirow[b]{2}{*}{ geometric parameters } & \multicolumn{3}{|c|}{ conformers } \\
\hline & I & II & III \\
\hline \multicolumn{4}{|c|}{ Bond $(\AA)$} \\
\hline $\mathrm{C}_{1}-\mathrm{C}_{2}$ & 1.501 & 1.509 & 1.509 \\
\hline $\mathrm{C}_{2}=\mathrm{O}_{6}$ & $1.216^{a}$ & 1.204 & 1.204 \\
\hline $\mathrm{C}_{2}-\mathrm{O}_{8}$ & 1.336 & 1.349 & 1.349 \\
\hline $\mathrm{O}_{8}-\mathrm{H}_{10}$ & 0.968 & 0.968 & 0.967 \\
\hline $\mathrm{C}_{1}-\mathrm{C}_{3}$ & 1.527 & 1.504 & 1.509 \\
\hline $\mathrm{C}_{3}=\mathrm{O}_{7}$ & 1.203 & 1.205 & 1.204 \\
\hline $\mathrm{C}_{3}-\mathrm{O}_{9}$ & 1.334 & 1.347 & 1.349 \\
\hline $\mathrm{O}_{9}-\mathrm{H}_{11}$ & $0.978^{a}$ & 0.967 & 0.967 \\
\hline $\mathrm{C}_{1}-\mathrm{H}_{4}$ & 1.086 & 1.088 & 1.087 \\
\hline $\mathrm{C}_{1}-\mathrm{H}_{5}$ & 1.092 & 1.087 & 1.087 \\
\hline \multicolumn{4}{|c|}{ Angle (deg) } \\
\hline $\mathrm{C}_{2} \mathrm{C}_{1} \mathrm{C}_{3}$ & 117.52 & 110.15 & 111.99 \\
\hline $\mathrm{C}_{1} \mathrm{C}_{2}=\mathrm{O}_{6}$ & 125.53 & 125.80 & 125.72 \\
\hline $\mathrm{O}_{6} \mathrm{C}_{2}-\mathrm{O}_{8}$ & 122.60 & 123.73 & 123.67 \\
\hline $\mathrm{C}_{2} \mathrm{O}_{8} \mathrm{H}_{10}$ & 106.78 & 106.08 & 106.33 \\
\hline $\mathrm{C}_{1} \mathrm{C}_{3}=\mathrm{O}_{7}$ & 120.18 & 125.08 & 125.72 \\
\hline $\mathrm{O}_{7} \mathrm{C}_{3}-\mathrm{O}_{9}$ & 122.52 & 123.90 & 123.67 \\
\hline $\mathrm{C}_{3} \mathrm{O}_{9} \mathrm{H}_{11}$ & 108.50 & 106.23 & 106.33 \\
\hline \multicolumn{4}{|c|}{ Dihedral Angle (deg) } \\
\hline $\mathrm{O}_{6}=\mathrm{C}_{2}-\mathrm{O}_{8} \mathrm{H}_{10}$ & -0.6 & -0.3 & 1.1 \\
\hline $\mathrm{O}_{6}=\mathrm{C}_{2} \mathrm{C}_{1} \mathrm{C}_{3}$ & -19.9 & -3.1 & -127.5 \\
\hline $\mathrm{O}_{7}=\mathrm{C}_{3}-\mathrm{O}_{9} \mathrm{H}_{11}$ & 176.4 & -3.0 & 1.1 \\
\hline $\mathrm{O}_{7}=\mathrm{C}_{3} \mathrm{C}_{1} \mathrm{C}_{2}$ & 164.1 & 98.3 & -127.5 \\
\hline $\mathrm{H}_{4} \mathrm{C}_{1} \mathrm{C}_{3} \mathrm{C}_{7}$ & -38.3 & -141.3 & -6.9 \\
\hline $\mathrm{H}_{5} \mathrm{C}_{1} \mathrm{C}_{2} \mathrm{C}_{6}$ & 100.0 & 116.6 & -6.9 \\
\hline $\mathrm{O}_{6} \cdots \mathrm{H}_{11}$ & 1.756 & & \\
\hline
\end{tabular}

${ }^{a} \mathrm{C}_{2}=\mathrm{O}_{6}$ and $\mathrm{O}_{9}-\mathrm{H}_{11}$ bond lengths in form I clearly show the intermolecular $\mathrm{O}_{9}-\mathrm{H}_{11} \cdots \mathrm{O}_{6}=\mathrm{C}_{2}$ hydrogen bond in this conformer, as they are clearly longer than in the free $\mathrm{O}-\mathrm{H}$ and $\mathrm{C}=\mathrm{O}$ bonds in the other conformers.

stable conformer, followed by conformers II and III. These two structures are predicted to be ca. $5 \mathrm{~kJ} \mathrm{~mol}^{-1}$ higher in energy, being of almost similar energy when compared with each other. On the other hand, the MP2 results show an interesting dependence on the basis set. In particular, increasing the flexibility of the basis set leads to a stabilization of conformer I relative to conformers II and III. Indeed, when the largest basis set is used, the MP2 calculated relative energies follow the same trend as those resulting from DFT calculations, with conformer I predicted as the lowest-energy conformer, followed by conformers II and III. The smaller basis sets at the MP2 level predict conformer II to be slightly lower in energy than conformer $\mathbf{I}$. These results are a direct consequence of the better description of the intramolecular hydrogen bond when the basis set is enlarged. Indeed, the $\mathrm{C}=\mathrm{O} \cdots \mathrm{H}$ hydrogen-bond distance becomes shorter with the increase of the basis set $[6-31 \mathrm{G}(\mathrm{d}, \mathrm{p})$, $183.1 \mathrm{pm} ; 6-311++\mathrm{G}(2 \mathrm{~d}, 2 \mathrm{p}), 178.5 \mathrm{pm} ; 6-311++\mathrm{G}(3 \mathrm{df}, 3 \mathrm{dp})$,
$175.6 \mathrm{pm}]$, indicating that this bond becomes stronger when the flexibility of the basis set is increased to describe the outer electrons.

It is interesting to note that the description of the intramolecular hydrogen bond in malonic acid from the B3LYP calculations seems to be rather insensitive to basis set. This observation can be correlated with the above-mentioned quasiinvariance of the B3LYP relative conformational energies with basis set. It is also reflected in the fact that the B3LYP-calculated $\mathrm{C}=\mathrm{O} \cdots \mathrm{H}$ hydrogen-bond distance in conformer $\mathbf{I}$ does not differ significantly with basis set [6-31G(d,p), $177.3 \mathrm{pm} ; 6-311++\mathrm{G}-$ (2d,2p), 177.8 pm; 6-311++G(3df,3dp), 177.1 pm]. Because the hydrogen-bond distances predicted by B3LYP calculations are close to the highest-level MP2/6-311++G(3df,3pd) calculations, it seems the DFT method provides a relatively good description of the intramolecular hydrogen bond in conformer I even when the relatively modest 6-31G(d,p) basis set is used. Moreover, for studies of larger dicarboxylic acids in progress in our laboratories, the B3LYP/6-31G(d,p) calculations can be favored over extensive MP2 calculations to obtain acceptable data on the conformer properties.

Near-Infrared-Induced Conformational Interconversions. Selective irradiation of the $\mathrm{OH}$ stretching fundamental vibrations has been found to be an elegant way to promote conformational isomerization processes in carboxylic compounds, ${ }^{19,20}$ although the elementary mechanism of IR-induced rotamerization is far from being completely understood. Recently, we have used an approach that is based on selective irradiation at a frequency matching that of the first overtone of the $\nu \mathrm{OH}$ vibration. ${ }^{18,21}$ This approach proved to be considerably more efficient in promoting conformational isomerization of matrix-isolated oxalic acid than irradiating one of the fundamental modes. Thus, it also appears to be a very promising technique for characterization of the conformational distribution of matrix-isolated malonic acid.

On the basis of previous NIR irradiation experiments performed in similar compounds, ${ }^{18,21}$ we expected the first overtones of the $\mathrm{OH}$ stretching vibrations of matrix-isolated malonic acid to occur in the $7000-6200 \mathrm{~cm}^{-1}$ region. Because the overtone bands are expected to be extremely weak, to tune the laser on the desired frequency, we began a systematic scanning within this spectral region, using a narrowband tunable laser source until changes were observed in the vibrational spectra. This approach has already been used successfully in previous studies. ${ }^{18,21}$ It constitutes a new method of finding overtones even when they cannot be recorded directly.

The IR spectrum of matrix-isolated malonic acid (nonirradiated sample) is shown in Figure $2\left(3700-3200 \mathrm{~cm}^{-1}\right.$ and 1900-1700 $\mathrm{cm}^{-1}$ regions). In the $\mathrm{OH}$ stretching region, the spectrum shows bands at $3570-3560 \mathrm{~cm}^{-1}$ and at $3550-3540$ $\mathrm{cm}^{-1}$, which are typical values for an $\mathrm{O}-\mathrm{H}$ group not involved in hydrogen bonding, and a broad band at $\cong 3250 \mathrm{~cm}^{-1}$, which can be assigned to an $\mathrm{O}-\mathrm{H}$ group participating in a strong intramolecular hydrogen bond. In the $\mathrm{C}=\mathrm{O}$ stretching region, a complex multiplet of bands appears in the $1815-1770 \mathrm{~cm}^{-1}$ region, typical of unperturbed carbonyl groups, beside the band at $1740 \mathrm{~cm}^{-1}$, which appears redshifted as a result of hydrogen bonding. The presence of these groups of bands clearly reveals the coexistence of more than one conformer in the matrix. One of the conformers exhibits an intramolecular hydrogen bond, and, taking into consideration the theoretical predictions, it corresponds to conformer $\mathbf{I}$.

Irradiation of the matrix at $6964 \mathrm{~cm}^{-1}$ led to an increase in the intensity of the bands that could be ascribed to the hydrogen- 


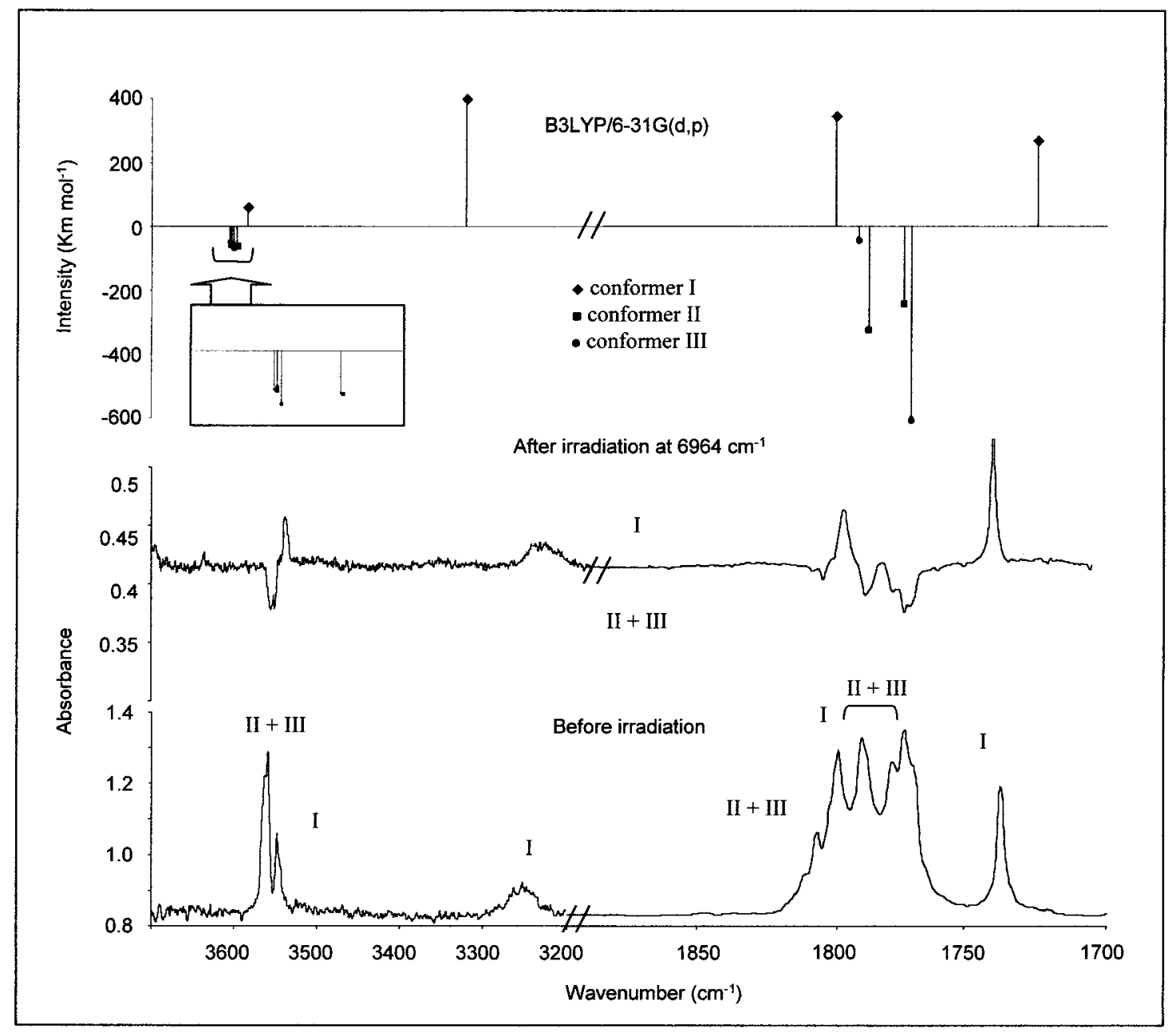

Figure 2. Infrared spectrum (3700-3200 $\mathrm{cm}^{-1}$ and $1900-1700 \mathrm{~cm}^{-1}$ regions) of malonic acid in an argon matrix at $7.5 \mathrm{~K}$ : difference spectrum (irradiated sample at $6964 \mathrm{~cm}^{-1}$ - nonirradiated sample), and B3LYP/6-31G(d,p) spectra of the three most stable conformers.

bonded conformer I (see Figure 2). Considering the theoretical results (relative conformational energies and vibrational spectrasee Table 1 and Figure 2), conformers II and III should correspond to the reactant species and give rise to the decreasing bands in the difference spectrum shown in Figure 2. Because the bands assigned to the $\mathrm{OH}$ stretching fundamentals of these two conformers differ by less than $3 \mathrm{~cm}^{-1}$, the corresponding overtones are expected to overlap considerably, and thus conformers II and III are being simultaneously pumped during irradiation at this wavenumber.

The bands at $3550-3540 \mathrm{~cm}^{-1}$ and $\cong 3250 \mathrm{~cm}^{-1}$, which increase during irradiation, are the $\mathrm{OH}$ stretching modes of the free and hydrogen-bonded $\mathrm{OH}$ groups of conformer $\mathbf{I}$, respectively. The decreasing bands are due to conformers II and III, which, accordingly to the calculations, give rise to bands at nearly the same frequency.

In the $\mathrm{C}=\mathrm{O}$ stretching region, the band at $1740 \mathrm{~cm}^{-1}$ corresponds to the stretching mode of the intramolecularly hydrogen-bonded carbonyl group of conformer I, while the component of the multiplet appearing near $1800 \mathrm{~cm}^{-1}$, which also increases in intensity upon irradiation, can be ascribed to the free carbonyl group of the same conformer. The remaining bands appearing in this spectral region are assigned to conformers II and III, as shown in Figure 2.

In a second series of experiments, the matrix was irradiated at 6920 or $6365 \mathrm{~cm}^{-1}$, pumping the first overtone of the $\mathrm{OH}$ stretching mode of the free or hydrogen-bonded $\mathrm{O}-\mathrm{H}$ groups of conformer I, respectively. Thus, once the population of conformer I was increased by irradiation at $6964 \mathrm{~cm}^{-1}$, backconversion of this conformer to II and III could be achieved. As shown in Figure 3, where we present the difference spectra, bands due to conformer I decrease whereas bands due to conformers II and III increase in intensity upon photolysis. The results obtained from irradiation at $6365 \mathrm{~cm}^{-1}$ were similar, but the process of conversion of conformer $\mathbf{I}$ into conformers II and III was found to be much less efficient than when irradiation at $6920 \mathrm{~cm}^{-1}$ was used. This possibly is due to the higher dispersion of the vibrational energy levels associated with the vibration being pumped $(\nu \mathrm{O}-\mathrm{H}$ of the intramolecularly H-bonded hydroxyl group) because of hydrogen bonding. The intramolecular interaction is also clearly manifested by the broadness of the vibrational band typically found for hydrogenbonded species. ${ }^{22}$

The irradiation experiments unequivocally confirmed the predictions made theoretically with respect to the nature of the most stable conformers of malonic acid. In particular, they allowed us to clearly identify the presence of conformer $\mathbf{I}$ in the matrixes, which is predicted by the highest-level calculations to be the lowest-energy conformer of malonic acid. Conformers II and III could also be identified from the detailed analysis of the spectra, although irradiation experiments alone were not enough to enable a positive discrimination between these two conformers.

Because the calculations predict very small energy differences among the three observed conformers (the highest-level MP2 calculated values are $<1.5 \mathrm{~kJ} \mathrm{~mol}^{-1}$; see Table 1 ), we tried to 


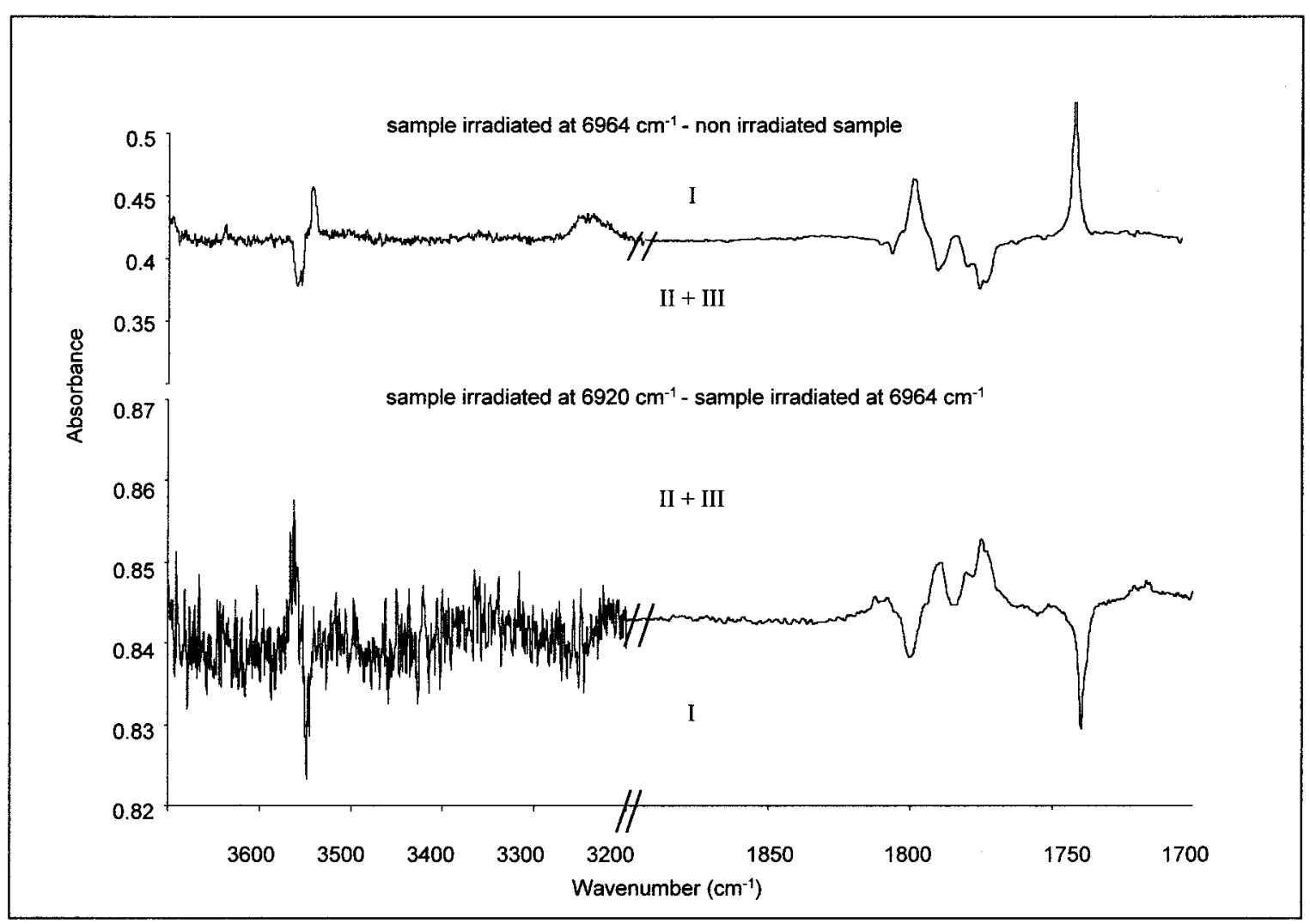

Figure 3. Infrared difference spectrum (3700-3200 $\mathrm{cm}^{-1}$ and $1900-1700 \mathrm{~cm}^{-1}$ regions) of malonic acid isolated in an argon matrix at $7.5 \mathrm{~K}$ : irradiated sample at $6964 \mathrm{~cm}^{-1}$ minus nonirradiated sample (top) and irradiated sample at $6920 \mathrm{~cm}^{-1}$ minus irradiated sample at $6964 \mathrm{~cm}{ }^{-1}$ (bottom).

promote thermally induced conformational isomerization by annealing a freshly prepared matrix to verify the theoretical predictions. This effort would require that energy barriers separating the various conformers be low enough to be overcome at experimentally accessible temperatures. However, annealing of the matrix up to $35 \mathrm{~K}$ led to no observable changes in the spectrum that would indicate conformational interconversions; thus we were unable to draw any definitive conclusion from the use of this method. On the other hand, these findings enable us to conclude that the energy barriers associated with the rotamerization reactions in an argon matrix are higher than 12 $\mathrm{kJ} \mathrm{mol}^{-1}$. $23^{2}$

Vibrational Assignments. The different behavior exhibited by the bands that could be ascribed to the conformers upon irradiation, as well as a comparison between the calculated and experimental spectra, enabled us to assign the IR spectrum of malonic acid. Table 3 presents the symmetry coordinates used to perform the normal coordinate analysis. Table 4 shows the experimental and calculated wavenumbers and potential energy distributions (PEDs).

The assignment of bands due to conformer I, based on the calculations and NIR irradiation experiments, is rather straightforward. On the other hand, because bands due to conformers II and III follow the same pattern of changes upon irradiation, the NIR experiments alone did not allow us to distinguish the bands due to each one of these forms. However, some evidence in the spectra supports the simultaneous presence of conformers II and III in the matrixes, as is pointed out below.

In the $\mathrm{C}=\mathrm{O}$ stretching region, at least six bands are observed between 1812 and $1771 \mathrm{~cm}^{-1}$ that are not due to conformer $\mathbf{I}$. These bands cannot be attributed to site effects alone because they spread over a relatively wide region. Therefore, the bands at 1790 and $1780 \mathrm{~cm}^{-1}$ were ascribed to the two $\mathrm{C}=\mathrm{O}$ stretching modes of conformer II (which were predicted at 1794 and 1781 $\mathrm{cm}^{-1}$, respectively), and the doublets appearing at 1812, 1808 $\mathrm{cm}^{-1}$ and $1775,1771 \mathrm{~cm}^{-1}$ were assigned to the vibrations of conformer III (calculated values: 1799 and $1778 \mathrm{~cm}^{-1}$ ), split as a result of matrix site effects.

In the $\mathrm{C}-\mathrm{O}$ stretching region, comparison with the computational predictions clearly indicates that the four observed bands not ascribable to conformer I must correspond to those expected in the presence of conformers II and III. Thus, the bands at 1379 and $1340 \mathrm{~cm}^{-1}$ are ascribed to conformer II, and those appearing at 1355 and $1334 \mathrm{~cm}^{-1}$ are assigned to conformer III. Note that the observed differences in frequencies between the two $\mathrm{C}-\mathrm{O}$ stretching modes belonging to the same conformer are in excellent agreement with the calculations, as follows: conformer II, exptl $35 \mathrm{~cm}^{-1} /$ calcd $25 \mathrm{~cm}^{-1}$; conformer III, exptl $21 \mathrm{~cm}^{-1} /$ calcd $22 \mathrm{~cm}^{-1}$ (see Table 4).

The analysis of other spectral regions also clearly indicates that both conformers II and III contribute to the spectrum. A complete assignment of bands to these forms, based essentially on the comparison between the observed and the calculated spectra (both frequencies and intensities were used), is given in Table 4, although some of the assignments should be considered tentative.

Some additional comments should be made concerning (1) the results of the PED calculations (see also Table 4) and (2) spectral evidence of the relative strength of the intramolecular hydrogen bond in malonic acid (conformer I) and in other relevant compounds.

(1) As is usual in this type of compound, the $\mathrm{C}-\mathrm{O}$ and $\mathrm{C}-\mathrm{C}$ stretching modes and the $\mathrm{COH}$ and $\mathrm{OCO}$ in-plane bending vibrations were found to be strongly coupled. This behavior is particularly evident in the case of the $\mathrm{C}-\mathrm{O}$ stretching mode of conformer I (calcd, $1362 \mathrm{~cm}^{-1}$; exptl, $1376 \mathrm{~cm}^{-1}$ ), where the $\mathrm{C}-\mathrm{O}$ stretching coordinate is not the calculated main contribution to the normal coordinate. However, the assignment made 
TABLE 3: Definition of the Internal Symmetry Coordinates Used in the Normal-Coordinate Analysis

\begin{tabular}{|c|c|c|c|c|c|}
\hline \multirow[b]{2}{*}{$\begin{array}{l}\text { coor- } \\
\text { dinate }\end{array}$} & \multirow[b]{2}{*}{$\begin{array}{c}\text { sym- } \\
\text { metry }\end{array}$} & \multicolumn{2}{|c|}{$\begin{array}{l}\text { approximate } \\
\text { description }\end{array}$} & \multicolumn{2}{|c|}{ definition $^{b}$} \\
\hline & & $\begin{array}{l}\text { conformer I } \\
\text { and } \\
\text { conformer II }\end{array}$ & $\begin{array}{l}\text { conformer } \\
\text { III }\end{array}$ & $\begin{array}{l}\text { conformer I } \\
\text { and } \\
\text { conformer II }\end{array}$ & $\begin{array}{l}\text { conformer } \\
\text { III }\end{array}$ \\
\hline S1 & $\mathrm{B}$ & $v \mathrm{C}=\mathrm{O}$ & $v \mathrm{C}=\mathrm{O}$ as & $v \mathrm{C}_{2}=\mathrm{O}_{6}$ & $v \mathrm{C}_{2}=\mathrm{O}_{6}-v \mathrm{C}_{3}=\mathrm{O}_{7}$ \\
\hline $\mathrm{S} 2$ & A & $v \mathrm{C}=\mathrm{O}^{\prime}$ & $v \mathrm{C}=\mathrm{O} \mathrm{s}$ & $v \mathrm{C}_{3}=\mathrm{O}_{7}$ & $v \mathrm{C}_{2}=\mathrm{O}_{6}+v \mathrm{C}_{3}=\mathrm{O}_{7}$ \\
\hline S3 & B & $v \mathrm{C}-\mathrm{O}$ & $v \mathrm{C}-\mathrm{O}$ as & $v \mathrm{C}_{2}-\mathrm{O}_{8}$ & $v \mathrm{C}_{2}-\mathrm{O}_{8}-v \mathrm{C}_{3}-\mathrm{O}_{9}$ \\
\hline S4 & A & $v \mathrm{C}-\mathrm{O}^{\prime}$ & $v \mathrm{C}-\mathrm{Os}$ & $v \mathrm{C}_{3}-\mathrm{O}_{9}$ & $v \mathrm{C}_{2}-\mathrm{O}_{8}+v \mathrm{C}_{3}-\mathrm{O}_{9}$ \\
\hline S5 & B & $v \mathrm{O}-\mathrm{H}$ & $v \mathrm{O}-\mathrm{H}$ as & $v \mathrm{O}_{8}-\mathrm{H}_{10}$ & $v \mathrm{O}_{8}-\mathrm{H}_{10}-v \mathrm{O}_{9}-\mathrm{H}_{11}$ \\
\hline S6 & A & $v \mathrm{O}-\mathrm{H}^{\prime}$ & $v \mathrm{O}-\mathrm{H} \mathrm{s}$ & $v \mathrm{O}_{9}-\mathrm{H}_{11}$ & $v \mathrm{O}_{8}-\mathrm{H}_{10}+v \mathrm{O}_{9}-\mathrm{H}_{11}$ \\
\hline S7 & B & $v \mathrm{C}-\mathrm{C}$ & $v \mathrm{C}-\mathrm{C}$ as & $v \mathrm{C}_{1}-\mathrm{C}_{2}$ & $v \mathrm{C}_{1}-\mathrm{C}_{2}-v \mathrm{C}_{1}-\mathrm{C}_{3}$ \\
\hline S8 & A & $v \mathrm{C}-\mathrm{C}^{\prime}$ & $v \mathrm{C}-\mathrm{C} \mathrm{s}$ & $v \mathrm{C}_{1}-\mathrm{C}_{3}$ & $v \mathrm{C}_{1}-\mathrm{C}_{2}+v \mathrm{C}_{1}-\mathrm{C}_{3}$ \\
\hline S9 & $\mathrm{B}$ & $v \mathrm{CH}$ & $v \mathrm{CH}_{2}$ as & $v \mathrm{C}_{1}-\mathrm{H}_{4}$ & $v \mathrm{C}_{1}-\mathrm{H}_{4}-v \mathrm{C}_{1}-\mathrm{H}_{5}$ \\
\hline $\mathrm{S} 10$ & A & $v \mathrm{CH}^{\prime}$ & $v \mathrm{CH}_{2} \mathrm{~s}$ & $v \mathrm{C}_{1}-\mathrm{H}_{5}$ & $v \mathrm{C}_{1}-\mathrm{H}_{4}+v \mathrm{C}_{1}-\mathrm{H}_{5}$ \\
\hline S11 & B & $\delta \mathrm{COH}$ & $\delta \mathrm{COH}$ as & $\delta \mathrm{C}_{2} \mathrm{O}_{8} \mathrm{H}_{10}$ & $\delta \mathrm{C}_{2} \mathrm{O}_{8} \mathrm{H}_{10}-\delta \mathrm{C}_{3} \mathrm{O}_{9} \mathrm{H}_{11}$ \\
\hline $\mathrm{S} 12$ & A & $\delta \mathrm{COH}^{\prime}$ & $\delta \mathrm{COH} \mathrm{s}$ & $\delta \mathrm{C}_{3} \mathrm{O}_{9} \mathrm{H}_{11}$ & $\delta \mathrm{C}_{2} \mathrm{O}_{8} \mathrm{H}_{10}+\delta \mathrm{C}_{3} \mathrm{O}_{9} \mathrm{H}_{11}$ \\
\hline S13 & $\mathrm{B}$ & $\delta \mathrm{OCO}$ & $\delta \mathrm{OCO}$ as & $2 \delta \mathrm{O}_{6} \mathrm{C}_{2} \mathrm{O}_{8}-\delta \mathrm{O}_{6} \mathrm{C}_{2} \mathrm{C}_{1}-\delta \mathrm{O}_{8} \mathrm{C}_{2} \mathrm{C}_{1}$ & $\begin{array}{c}2 \delta \mathrm{O}_{6} \mathrm{C}_{2} \mathrm{O}_{8}-\delta \mathrm{O}_{6} \mathrm{C}_{2} \mathrm{C}_{1}-\delta \mathrm{O}_{8} \mathrm{C}_{2} \mathrm{C}_{1}-2 \delta \mathrm{O}_{7} \mathrm{C}_{3} \mathrm{O}_{9}+ \\
\quad \delta \mathrm{O}_{7} \mathrm{C}_{3} \mathrm{C}_{1}+\delta \mathrm{O}_{9} \mathrm{C}_{3} \mathrm{C}_{1}\end{array}$ \\
\hline S14 & A & $\delta \mathrm{OCO}^{\prime}$ & $\delta \mathrm{OCO} \mathrm{s}$ & $2 \delta \mathrm{O}_{7} \mathrm{C}_{3} \mathrm{O}_{9}-\delta \mathrm{O}_{7} \mathrm{C}_{3} \mathrm{C}_{1}-\delta \mathrm{O}_{9} \mathrm{C}_{3} \mathrm{C}_{1}$ & $\begin{array}{l}2 \delta \mathrm{O}_{6} \mathrm{C}_{2} \mathrm{O}_{8}-\delta \mathrm{O}_{6} \mathrm{C}_{2} \mathrm{C}_{1}-\delta \mathrm{O}_{8} \mathrm{C}_{2} \mathrm{C}_{1}+2 \delta \mathrm{O}_{7} \mathrm{C}_{3} \mathrm{O}_{9}- \\
\delta \mathrm{O}_{7} \mathrm{C}_{3} \mathrm{C}_{1}-\delta \mathrm{O}_{9} \mathrm{C}_{3} \mathrm{C}_{1}\end{array}$ \\
\hline S15 & B & $\delta \mathrm{CC}=\mathrm{O}$ & $\delta \mathrm{CC}=\mathrm{O}$ as & $\delta \mathrm{O}_{6} \mathrm{C}_{2} \mathrm{C}_{1}-\delta \mathrm{O}_{8} \mathrm{C}_{2} \mathrm{C}_{1}$ & $\delta \mathrm{O}_{6} \mathrm{C}_{2} \mathrm{C}_{1}-\delta \mathrm{O}_{8} \mathrm{C}_{2} \mathrm{C}_{1}-\delta \mathrm{O}_{7} \mathrm{C}_{3} \mathrm{C}_{1}+\delta \mathrm{O}_{9} \mathrm{C}_{3} \mathrm{C}_{1}$ \\
\hline S16 & A & $\delta \mathrm{CC}=\mathrm{O}^{\prime}$ & $\delta \mathrm{CC}=\mathrm{O} \mathrm{s}$ & $\delta \mathrm{O}_{7} \mathrm{C}_{3} \mathrm{C}_{1}-\delta \mathrm{O}_{9} \mathrm{C}_{3} \mathrm{C}_{1}$ & $\delta \mathrm{O}_{6} \mathrm{C}_{2} \mathrm{C}_{1}-\delta \mathrm{O}_{8} \mathrm{C}_{2} \mathrm{C}_{1}+\delta \mathrm{O}_{7} \mathrm{C}_{3} \mathrm{C}_{1}-\delta \mathrm{O}_{9} \mathrm{C}_{3} \mathrm{C}_{1}$ \\
\hline S17 & A & $\delta \mathrm{CH}_{2}$ & $\delta \mathrm{CH}_{2}$ & $\begin{array}{c}5 \delta \mathrm{H}_{4} \mathrm{C}_{1} \mathrm{H}_{5}-\delta \mathrm{C}_{2} \mathrm{C}_{1} \mathrm{H}_{4}-\delta \mathrm{C}_{2} \mathrm{C}_{1} \mathrm{H}_{5}-\delta \mathrm{C}_{3} \mathrm{C}_{1} \mathrm{H}_{4}- \\
\quad \delta \mathrm{C}_{3} \mathrm{C}_{1} \mathrm{H}_{5}-\delta \mathrm{C}_{2} \mathrm{C}_{1} \mathrm{C}_{3}\end{array}$ & $c$ \\
\hline $\mathrm{S} 18$ & A & $\delta \mathrm{CCC}$ & $\delta \mathrm{CCC}$ & $\begin{array}{l}4 \delta \mathrm{C}_{2} \mathrm{C}_{1} \mathrm{C}_{3}-\delta \mathrm{C}_{2} \mathrm{C}_{1} \mathrm{H}_{4}-\delta \mathrm{C}_{2} \mathrm{C}_{1} \mathrm{H}_{5}-\delta \mathrm{C}_{3} \mathrm{C}_{1} \mathrm{H}_{4}- \\
\delta \mathrm{C}_{3} \mathrm{C}_{1} \mathrm{H}_{5}\end{array}$ & $c$ \\
\hline S19 & B & $\omega \mathrm{CH}_{2}$ & $\omega \mathrm{CH}_{2}$ & $\delta \mathrm{C}_{2} \mathrm{C}_{1} \mathrm{H}_{4}+\delta \mathrm{C}_{2} \mathrm{C}_{1} \mathrm{H}_{5}-\delta \mathrm{C}_{3} \mathrm{C}_{1} \mathrm{H}_{4}-\delta \mathrm{C}_{3} \mathrm{C}_{1} \mathrm{H}_{5}$ & $c$ \\
\hline S20 & B & $\tau \mathrm{CH}_{2}$ & $\tau \mathrm{CH}_{2}$ & $\delta \mathrm{C}_{2} \mathrm{C}_{1} \mathrm{H}_{4}-\delta \mathrm{C}_{2} \mathrm{C}_{1} \mathrm{H}_{5}-\delta \mathrm{C}_{3} \mathrm{C}_{1} \mathrm{H}_{5}+\delta \mathrm{C}_{3} \mathrm{C}_{1} \mathrm{H}_{4}$ & $c$ \\
\hline S21 & A & $\gamma \mathrm{CH}_{2}$ & $\gamma \mathrm{CH}_{2}$ & $\delta \mathrm{C}_{2} \mathrm{C}_{1} \mathrm{H}_{4}-\delta \mathrm{C}_{2} \mathrm{C}_{1} \mathrm{H}_{5}+\delta \mathrm{C}_{3} \mathrm{C}_{1} \mathrm{H}_{5}-\delta \mathrm{C}_{3} \mathrm{C}_{1} \mathrm{H}_{4}$ & $c$ \\
\hline $\mathrm{S} 22$ & $\mathrm{~B}$ & $\gamma \mathrm{C}=\mathrm{O}$ & $\gamma \mathrm{C}=\mathrm{O}$ as & $\gamma \mathrm{C}_{2}=\mathrm{O}_{6}$ & $\gamma \mathrm{C}_{2}=\mathrm{O}_{6}-\gamma \mathrm{C}_{3}=\mathrm{O}_{7}$ \\
\hline S23 & A & $\gamma \mathrm{C}=\mathrm{O}^{\prime}$ & $\gamma \mathrm{C}=\mathrm{Os}$ & $\gamma \mathrm{C}_{3}=\mathrm{O}_{7}$ & $\gamma \mathrm{C}_{2}=\mathrm{O}_{6}+\gamma \mathrm{C}_{3}=\mathrm{O}_{7}$ \\
\hline S24 & $\mathrm{B}$ & $\tau \mathrm{C}-\mathrm{O}$ & $\tau \mathrm{C}-\mathrm{O}$ as & $\tau \mathrm{C}_{2}-\mathrm{O}_{8}$ & $\tau \mathrm{C}_{2}-\mathrm{O}_{8}-\tau \mathrm{C}_{3}-\mathrm{O}_{9}$ \\
\hline S25 & A & $\tau \mathrm{C}-\mathrm{O}^{\prime}$ & $\tau \mathrm{C}-\mathrm{O} \mathrm{s}$ & $\tau \mathrm{C}_{3}-\mathrm{O}_{9}$ & $\tau \mathrm{C}_{2}-\mathrm{O}_{8}+\tau \mathrm{C}_{3}-\mathrm{O}_{9}$ \\
\hline S26 & $\mathrm{B}$ & $\tau \mathrm{C}-\mathrm{C}$ & $\tau \mathrm{C}-\mathrm{C}$ as & $\tau \mathrm{C}_{1}-\mathrm{C}_{2}$ & $\tau \mathrm{C}_{1}-\mathrm{C}_{2}-\tau \mathrm{C}_{1}-\mathrm{C}_{3}$ \\
\hline S27 & A & $\tau \mathrm{C}-\mathrm{C}^{\prime}$ & $\tau \mathrm{C}-\mathrm{C} \mathrm{s}$ & $\tau \mathrm{C}_{1}-\mathrm{C}_{3}$ & $\tau \mathrm{C}_{1}-\mathrm{C}_{2}+\tau \mathrm{C}_{1}-\mathrm{C}_{3}$ \\
\hline
\end{tabular}

${ }^{a}$ Symmetry species refers to the higher-symmetry conformer $\left(C_{2}\right) .{ }^{b}$ For atom numbering, see Figure $1 \nu$, stretching; $\delta$, bending; $\gamma$, rocking; $\tau$, torsion. ${ }^{c}$ Same definition as for conformers I and II.

here is unequivocal, because the dominant contribution is due to the $\delta \mathrm{CH}_{2}$ scissoring coordinate, which is by far the major component of the normal mode corresponding to the $1387 \mathrm{~cm}^{-1}$ calculated frequency (obsd, 1402-1392 $\mathrm{cm}^{-1}$; site split band).

(2) In oxalic acid $\left[(\mathrm{C}(=\mathrm{O}) \mathrm{OH})_{2}\right.$, the smallest dicarboxylic acid], the redshift observed in the $\mathrm{O}-\mathrm{H}$ stretching vibration upon intramolecular hydrogen-bond formation, $\Delta v \mathrm{OH}$, is $70 \mathrm{~cm}^{-1} .^{18}$ In malonic acid this shift is much larger $\left(\cong 295 \mathrm{~cm}^{-1}\right)$. Therefore, the intramolecular hydrogen bond in this compound is much stronger than in oxalic acid; this is due mostly to the greater conformational flexibility of malonic acid, which allows a better interaction geometry. The intramolecular hydrogen bond in malonic acid is even stronger than in glycolic acid $(\Delta \nu \mathrm{OH}=$ $\left.80 \mathrm{~cm}^{-1}\right) .^{24}$

Observed versus Calculated Population of Conformational States. The relative populations of the three observed conformers can be estimated from the experimental IR band intensities recorded immediately after deposition, taking into account the calculated intensities and assuming that no conformational isomerization takes place during the deposition process.

To perform these calculations, we first corrected the predicted intensities [B3LYP/6-31G(d,p)] of selected bands ascribable to conformer I or conformers II and III so that their intensity ratios to the corresponding $\mathrm{C}=\mathrm{O}$ stretching bands were equal to those observed in the IR difference spectra (irradiated sample minus nonirradiated sample). Calculations took into account the different degeneracies of the conformational states. The following equation was used:

$$
I_{i}^{\mathrm{corr}}=\frac{\Delta I_{i}^{\exp }}{\Delta I^{\exp (v C=O)}} I^{\operatorname{calc}(v C=O)}
$$

where $I$ stands for integrated intensity, $i$ refers to a given vibrational mode, and $\Delta I$ is an observed intensity in the difference spectrum. Bands that originated in the $\mathrm{C}=\mathrm{O}$ and $\mathrm{O}-\mathrm{H}$ stretching modes were selected for use in estimating relative populations because they appear in relatively clear spectral regions.

The (conformer II + conformer III): conformer I population ratio at $323 \mathrm{~K}$ calculated in this way is $77: 23 \%$, a value that is in agreement with the results of the $[\mathrm{MP} 2 / 6-311++\mathrm{G}(3 \mathrm{df}, 3 \mathrm{pd})]$ calculations $(71: 29 \%)$, suggesting the absence of conformational relaxation during deposition. Note that conformer II is a doubly degenerated species.

It is important to note that the agreement between the experimental and calculated relative populations is achieved only when the extended $6-311++\mathrm{G}(3 \mathrm{df}, 3 \mathrm{pd})$ basis set and the MP2 level of theory are used. When relative conformational energies resulting from the DFT calculations are used, the population of conformer $\mathbf{I}$ is predicted to be considerably higher than the experimentally determined value (higher than 60\%), indicating that the DFT calculations systematically overestimate the relative energy differences between conformers II and III and the conformational ground state (I). On the other hand, the good agreement obtained at the highest level of theory [MP2/6$311++\mathrm{G}(3 \mathrm{df}, 3 \mathrm{pd})]$ strongly supports these theoretical results concerning relative conformational energies. 
TABLE 4: Observed and Calculated $\left(\operatorname{Scaled}^{a}\right)$ B3LYP/6-31G(d,p) Frequencies of the Three Most Stable Conformers of Malonic Acid Isolated in an Argon Matrix

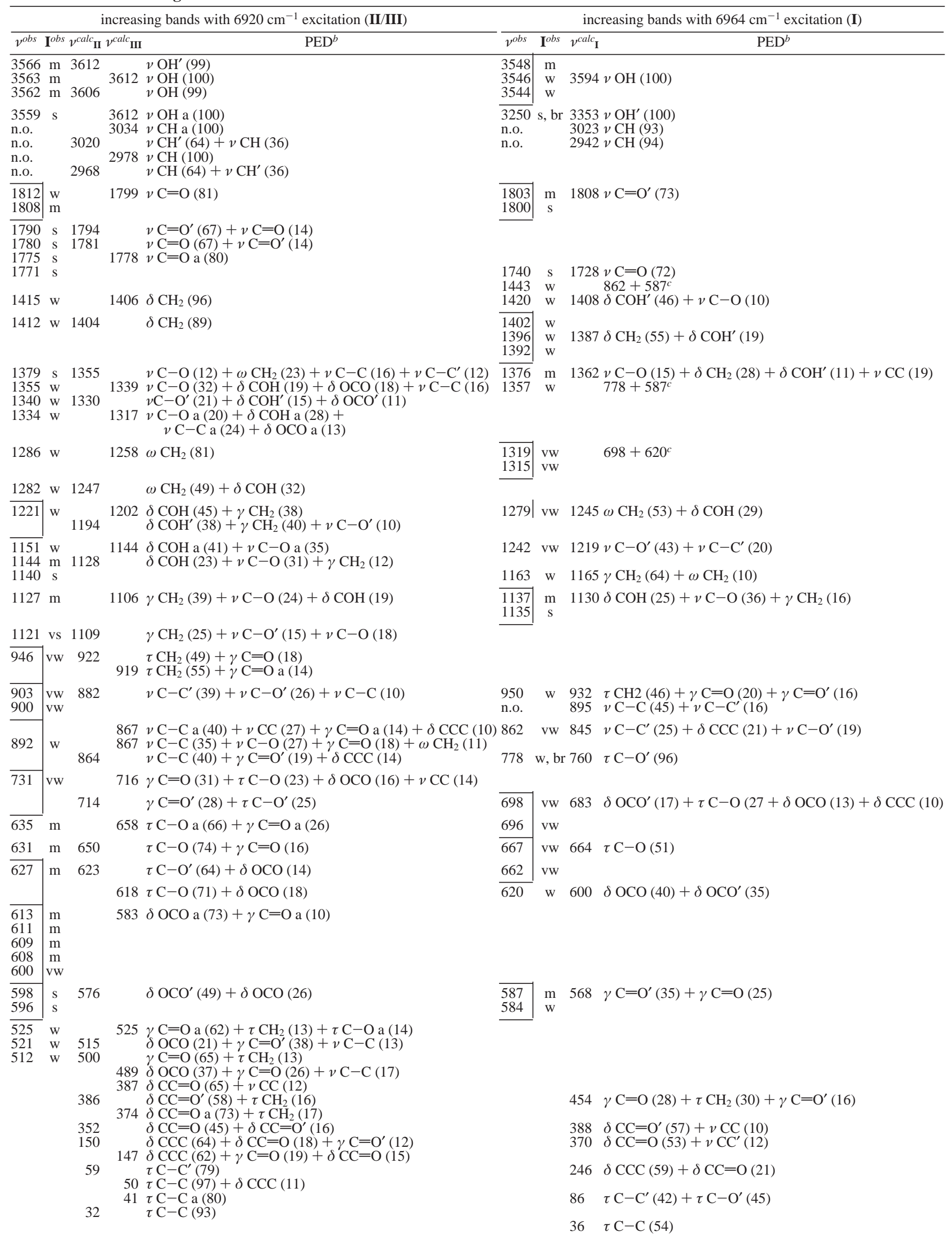

${ }^{a}$ Scale factor $0.9614 .{ }^{b}$ Only contributions higher than $10 \%$ are listed. ${ }^{c}$ Tentative assignment as combination bands. $\nu$, stretching; $\delta$, bending; $\tau$, torsion; $\gamma$, rocking; n.o., not observed; br, broad; vs, very strong; s, strong; m, medium; w, weak; vw, very weak. 


\section{Conclusion}

The use of narrowband tunable NIR irradiation in the $\mathrm{OH}$ stretching first-overtone region of malonic acid allowed us to promote the interconversion between the three low-energy conformers of this molecule. These conformers were already present in the matrix before irradiation. On the other hand, thermally induced isomerization could not be observed upon annealing the matrix up to $35 \mathrm{~K}$, indicating that the energy barriers associated with these isomerization processes are higher than $12 \mathrm{~kJ} \mathrm{~mol}^{-1}$. Assuming that no rotamerization occurs during deposition, it was possible to characterize the conformational equilibrium of malonic acid in the gas phase at the temperature used in this study to sublimate the substance $(323 \mathrm{~K})$. Unfortunately, it was not possible to selectively pump conformer II and conformer III, because these two forms have very similar $\mathrm{OH}$ stretching frequencies, although the global analysis of the vibrational data clearly indicates that these two conformers are present in the low-temperature matrix.

We could not observe any new bands in the IR spectra of the irradiated matrixes, which demonstrates that no conformational conversion into higher-energy conformers is promoted by vibrational excitation. This fact indicates that for the matrixisolated molecules, the energy barriers associated with these processes are above the excitation energy $\left(\simeq 83 \mathrm{~kJ} \mathrm{~mol}^{-1}\right)$.

Including multiple polarization and diffuse functions in the basis set used to perform the MP2 calculations proved essential to a correct evaluation of the relative conformational energies in malonic acid. Our results support the use of these basis sets when considering relative energies of different conformers of molecules where intramolecular hydrogen bonding plays an important role. The B3LYP calculations were able to reproduce the MP2/6-311++G(3df,3pd) ordering when more modest basis sets were used, which indicates that this economical approach could be employed for larger systems of a similar nature.

Acknowledgment. The authors acknowledge financial support from Academy of Finland. R.F. also appreciates financial support from Fundação para a Ciência e a Tecnologia, Lisbon, Portugal (research project PRAXIS/P/QUI/10137/1998).

\section{References and Notes}

(1) Roedern, E. G.; Grams, F.; Brandstetter, H.; Moroder, L. J. Med. Chem. 1998, 41, 339.

(2) Derbyshire, W.; Gorvin, T. C.; Warmer, D. J. Mol. Phys. 1969, $17,401$.

(3) Ganguly, S.; Fernandes, J. R.; Desiraju, G. R.; Rao, C. N. Chem. Phys. Lett. 1980, 69, 227.
(4) Rao, C. N.; Ganguly, S.; Swamy, H. R. Croat. Chem. Acta 1982, 55,207

(5) Goedkoop, J. A.; Macgillavry, C. H. Acta Crystallogr. 1957, 10, 125.

(6) Delaplane, R. C.; David, W. I. F.; Wilson, C. C. Chem. Phys. Lett. 1993, 201, 75 .

(7) Fausto, R.; Maçôas, E. M. S.; Kulbida, A. J. Mol. Struct. 1999, 480-481, 83

(8) Merchán, M.; Tomás, F.; Nebot-Gil, I. J. Mol. Struct. (THEOCHEM) 1984, 109, 51

(9) Tarakeshwar, P.; Manogaran, S. J. Mol. Struct. (THEOCHEM) 1996, $362,77$.

(10) Hehre, J. W.; Ditchefield, R.; Pople, J. A. J. Chem. Phys. 1972, $56,2257$.

(11) (a) Møller, C.; Plesset, M. S. Phys. Rev. 1934, 46, 618. (b) Brinkley, J. S.; Pople, J. A. Int. J. Quantum Chem. 1975, 9, 229.

(12) (a) Becke, A. D. J. Chem. Phys. 1993, 98, 5648. (b) Lee, C.; Yang, W.; Parr, R. G. Phys. Rev. 1988, B37, 785; Miehlich, B.; Savin, A.; Stoll, H.; Preuss, H. Chem. Phys. Lett. 1989, 157, 200.

(13) (a) Frisch, M. J.; Trucks, G. W.; Schlegel, H. B.; Gill, P. M. W.; Johnson, B. G.; Wong, M. W.; Foresman, J. B.; Robb, M. A.; Head-Gordon, M.; Replogle, E. S.; Gomperts, R.; Andres, J. L.; Raghavachari, K.; Binkley, J. S.; Gonzalez, C.; Martin R. L.; Fox, D. J.; Defrees, D. J.; Baker, J.; Stewart, J. J. P.; Pople, J. A. GAUSSIAN92 DFT (revision G.2); Gaussian Inc.: Pittsburgh, PA, 1993. (b) Frisch, M. J.; Trucks, G. W.; Schlegel, H. B.; Gill, P. M. W.; Johnson, B. G.; Robb, M. A.; Cheeseman, J. R.; Keith, T.; Petersson, G. A.; Montgomery, J. A.; Raghavachari, K.; Al-Laham, M. A.; Zakrzewski, V. G.; Ortiz, J. V.; Foresman, J. B.; Cioslowski, J.; Stefanov, B. B.; Nanayakkara, A.; Challacombe, M.; Peng, C. Y.; Ayala, P. Y.; Chen, W.; Wong, M. W.; Andres, J. L.; Replogle, E. S.; Gomperts, R.; Martin, R. L.; Fox, D. J.; Binkley, J. S.; Defrees, D. J.; Baker, J.; Stewart, J. J. P.; Head-Gordon, M.; Gonzalez, C.; Pople, J. A. GAUSSIAN 94, Revision B 1; Gaussian Inc.: Pittsburgh, PA, 1995.

(14) Clark, T.; Chandrasekhar, J.; Spitznagel, G. W.; Schleyer, P. V. R. J. Comput. Chem. 1983, 4, 294.

(15) Frisch, M. J.; Pople, J. A.; Binkley, J. S. J. Chem. Phys. 1984, 80, 3265 .

(16) Fausto R. TRANSFORMER (version 2.0); Chemistry Department, University of Coimbra: Coimbra, Portugal, 1997.

(17) Faria, M. D. G.; Fausto R. BUILD-G (version 2.0) and VIBRAT (version 2.0); Chemistry Department, University of Coimbra: Coimbra, Portugal, 1997. (These programs incorporate several routines from programs GMAT and FPERT: Fuher, H.; Kartha, V. B.; Krueger, P. J.; Mantsch, H. H. Natl. Res. Council Can. Bull. 1976, 15, 1.

(18) Maçôas, E. M. S.; Fausto, R.; Pettersson, M.; Khriachtchev, L.; Räsänen, M. J. Phys. Chem. A 2000, 104, 6956.

(19) Fausto, R. Low-Temperature Molecular Spectroscopy; Fausto, R., Ed.; NATO Advanced Study Institute Series C483; Kluwer Academic: Amsterdam, 1996; p 125.

(20) Nieminen, J.; Räsänen, M.; Murto, J. J. Phys. Chem. 1992, 96 , $5303-5308$

(21) Pettersson, M.; Lundell, J.; Khriachtchev, L.; Räsänen, M. J. Am. Chem. Soc. 1997, 119, 11715.

(22) Pimentel, G. C.; McLellan, A. C. The Hydrogen Bond; W. H. Freeman: San Francisco, 1960.

(23) Barnes, A. J. J. Mol. Struct. 1984, 113, 161.

(24) Redington, R. L.; Liang, C. K. J. Mol. Spectrosc. 1984, 104, 25 